\title{
Home-Automation using Arduino-UNO Board and Android App
}

\author{
Zatin Gupta \\ Assistant Professor \\ RKGIT, Ghaziabad
}

\author{
Tanay Sen \\ B.Tech Scholar \\ RKGIT
}

\author{
Vinayak Gupta \\ B.Tech Scholar \\ RKGIT
}

\author{
Vaishnavi \\ B.Tech Scholar \\ RKGIT
}

\author{
Vijay \\ B.Tech Scholar \\ RKGIT
}

\begin{abstract}
Home Automation is exactly what the words sound like: Automating your home with the ability to control your home from smart plug to water leak sensors to automatic on/off electronics with a click. In this paper smart automation control for home electric equipments, optimizing the use of energy is developed. The proposed system makes use of Arduino Board, Bluetooth Module \& Android apk for controlling the system. Initially Android application developed is installed on Mobile device \& Bluetooth connection is established between the system and Mobile. Once Connection is established, system can be controlled by Mobile device.
\end{abstract}

\section{Keywords}

Home Automation System, Android Apk, Bluetooth Module

\section{INTRODUCTION}

Home automation is the way that all of our devices and appliances will be networked together to provide us with a seamless control over all aspects of our home and more. With home automation, you dictate how a device should react, when it should react, and why it should react. You set the schedule and the rest is automated and based off of your personal preferences thus providing convenience, control, money Savings, an overall smarter home.

Home automation begins with a high degree of energy awareness. An energy monitoring system may be able to deliver these insights via its user interface (usually in the form of an app or web portal), but a good HEMS (Home Energy Management System) will offer the same - plus the ability to take control as well

The home automation market is further segmented by networking technology into wired systems, power-line systems, computing networks, and wireless systems. Wireless system segment of home automation technology held the highest revenue share accounting for more than fifty percent of the overall market in 2013. With the increase in number of products equipped with $\mathrm{Wi}-\mathrm{Fi}$ technology, the demand for wireless technology enabled home automation solutions are observing substantial growth globally. Power-line systems is analyzed to be the second fastest growing networking technology segment after wireless systems and is expected to attain a significant growth in the recent future.

Home automation is very promising area its main benefits range from increased comfort greater safety \& security to a more rational use of energy and other resources allowing for significant savings . It also offers powerful means for helping and supporting the special need so $f$ people with disabilities and in particular the elderly. This application is very important and will steadily increase in the future.

\section{LITERATURE SURVEY}

Zatin Singhal [1] presented a paper on A2Z Control SystemDTMF Control System. This Control System has two relays to operate two devices such as to charge mobile phone and to blow the bulb.

Sunen Soni [2] presented a research paper on HomeAutomation using Arduino. In this System Web Server is used to host the Control of device.

Satish Palaniappan [3] presented a research paper on Home Automation System-A Study. In this paper GSM modem is used for sending Acknowledgement message .

Shubhankar Chattoraj [4] discussed an approach for designing an Automation using Arduino and also presented a research paper named Smart Home Automation based on different Sensors and Arduino as Master Controller.

Harsh Mehta [5] has presented a design and research paper on IOT based Home Automation System using Arduino Board. This paper describes the use of Internet of Things in development of Smart Home Automation.

\section{PROPOSED SYSTEM}

The system has two parts, namely; hardware and software. The hardware system consists of Arduino UNO board, Bluetooth Module HC-05, and home appliances.

The software system consists of a java based android application also Arduino language is used to configure the Arduino UNO board. These hardware components are used in order to control the home appliances. Arduino UNO board will help to develop an interface between the hardware and the software application.

This system also consists of a software application which is developed using android. The Bluetooth Module will help in transmitting and receiving the input given by the user. 


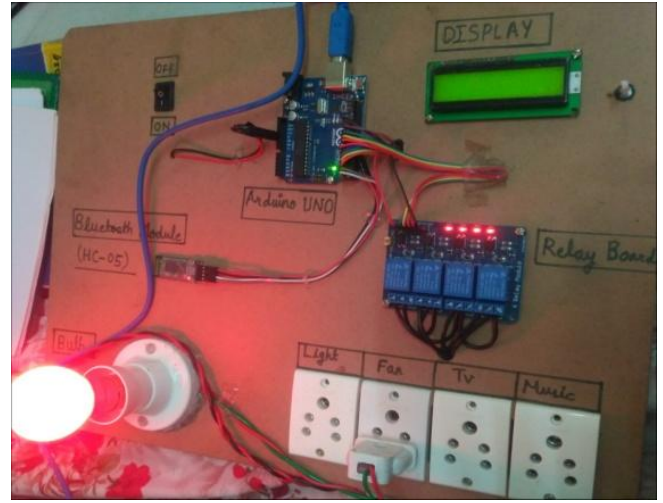

Fig-1: Proposed System

This system is mainly consist of three Components namely Arduino board, Bluetooth Module and Android Application. This system is controlled by Android application which establishes the connection with Bluetooth module HC-05 and command are send via Bluetooth to Arduino.

\subsection{Android}

Android was built from the ground-up to enable developers to create compelling mobile applications that take full advantage of all a handset has to offer. It was built to be truly open. For example, an application can call upon any of the phone's core functionality such as making calls, sending text messages, or using the camera, allowing developers to create richer and more cohesive experiences for users. Android is built on the open Linux Kernel. Furthermore, it utilizes a custom virtual machine that was designed to optimize memory and hardware resources in a mobile environment. Android is open source; it can be liberally extended to incorporate new cutting edge technologies as they emerge. The platform will continue to evolve as the developer community works together to build innovative mobile applications.

\subsection{Android Application}

An Android app is a software application running on the Android platform. Because the Android platform is built for mobile devices, a typical Android app is designed for a smartphone or a tablet PC running on the Android OS. Android apps are written in the Java programming language and use Java core libraries.

They are first compiled to Dalvik executables to run on the Dalvik virtual machine, which is a virtual machine specially designed for mobile devices.

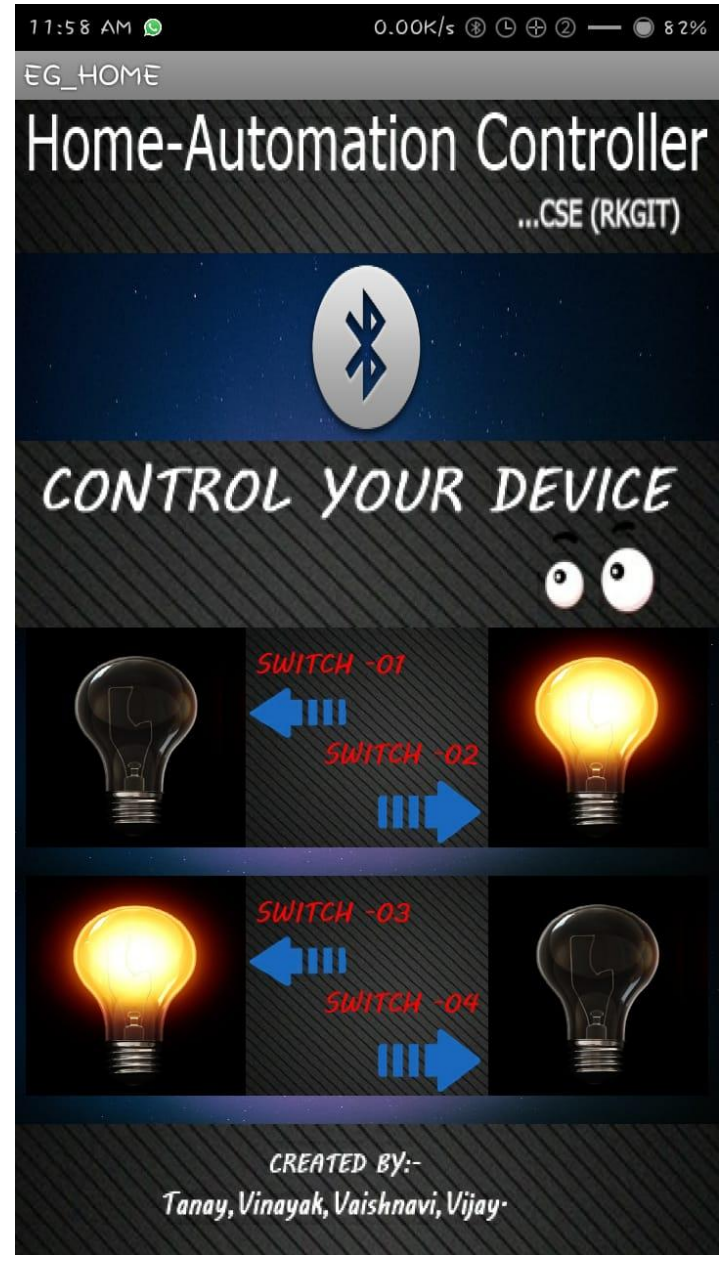

Fig-2: Android Application to Control System

\subsection{Arduino Board}

Arduino is an open-source platform used for building electronics projects. Arduino consists of both a physical programmable circuit board (often referred to as a microcontroller) and a piece of software, or IDE (Integrated Development Environment) that runs on your computer, used to write and upload computer code to the physical board.

The Arduino platform has become quite popular with people just starting out with electronics, and for good reason. Unlike most previous programmable circuit boards, the Arduino does not need a separate piece of hardware (called a programmer) in order to load new code onto the board - you can simply use a USB cable. Additionally, the Arduino IDE uses a simplified version of $\mathrm{C}++$, making it easier to learn to program. Finally, Arduino provides a standard form factor that breaks out the functions of the micro-controller into a more accessible package. The UNO is the best board to get started with electronics and coding. If this is your first experience tinkering with the platform, the UNO is the most robust board you can start playing with. The UNO is the most used and documented board of the whole Arduino family. 


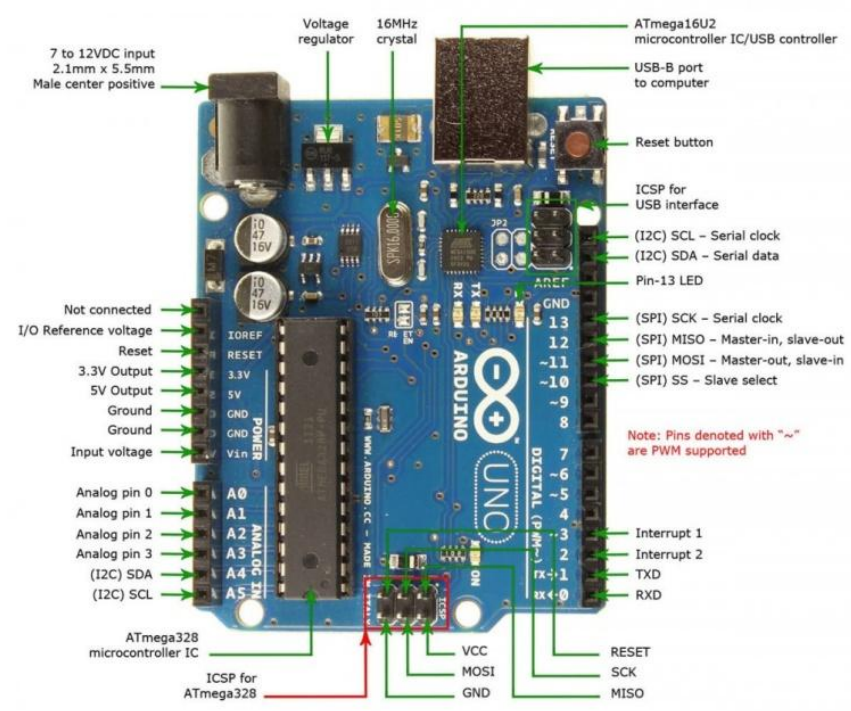

Fig-3 : Arduino Uno Board

\subsection{Bluetooth Module}

HC-05 is a Bluetooth module which is designed for wireless communication. This module can be used in a master or slave configuration. Comparing it to the HC-06 module, which can only be set as a Slave, the HC-05 can be set as Master as well which enables making a communication between two separate Arduino Boards

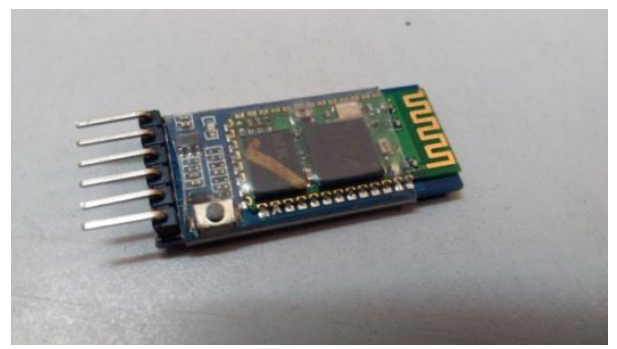

Fig-4 : Bluetooth Module HC-05

\section{WHY ARDUINO?}

1. Nearly instantaneous start (plug in a USB cord and load an example program and you can see something work)

2. A huge community of people working in the same environment.

3. A large assortment of included libraries for interfacing to a wide range of hardware.

4. Ease of use. The Arduino Uno has built in pinouts for providing you with $5 \mathrm{v}, 3.3 \mathrm{~V}$, ground, analog input, digital output, SPI, I2C which comes in handy.

5. Supported in all Operating System.

\section{Arduino Vs Rasperberry pi}

An Arduino is a micro-controller which provides an open source platform to build hardware and software environment. From opening your garage door remotely to making a DIY robot for your home security, Arduino provides limitless possibilities for the tinkerers and electronics enthusiasts.

The Raspberry Pi introduced in 2012, is a full-fleged computer which can do tasks like your desktop PC. From creating a web-server to making a gaming console for retro gaming, Raspberry Pi helps you to push your limits in coding and designing electronics circuits.

\section{CONCLUSION}

In this paper, architecture for low cost and flexible home control using Android based Smart phone is proposed and implemented. The proposed architecture utilizes a Bluetooth communication as an interoperable application layer for communicating between the remote user and home devices. Any Android based mobile device can install the apk file to control the system.

\section{REFERENCES}

To complete this paper successfully we need to refer with many websites and papers some of them are as mentioned below:

[1] A2Z Control System- DTMF Control System Er.Zatin Gupta $^{1}$, Payal Jain ${ }^{2}$, Monika ${ }^{3}$ Global Journal of Computer Science \& Technology, Volume: 10 , Issue : 11 | Oct 2010

[2] Home Automation System Using Arduino Sunen Soni ${ }^{1}$, Mayank Thanvi, Shivam Sharma, Sunil yadav, Vikas Singh IOSR Journal of Computer Engineering (IOSRJCE) E-ISSN: 2278-0661,p-ISSN:2278-8727 PP3 34-38

[3]Home Automation Systems -A Study Satish Palaniappan ${ }^{1}$ ,Navin Hariharan ${ }^{2}$, Naren $T$ kesh $^{3}$, Vidyalakshmi $\mathrm{S}^{4}$, Angel Deborah $\mathrm{S}^{5}$. International Journal of Computer Application(0975-8887) Volume: 116- 11,April ,2015

[4] Smart Home Automation based on different sensors and Arduino as the master controller Subhankar Chattoraj International Journal of Scientific and Research Publications Volume 5,Issue 10,October 2015 ISSN 2250-3153

[5] IOT BASED HOME AUTOMATION SYSTEM USING ARDUINO BOARD Harsh Mehta, Kunal Jadhav,Avinash Mishra,Prof. Anushree Deshmukh International Research Journal of Engineering and Technology(IRJET) Volume:04 Issue:01| Jan-2017 